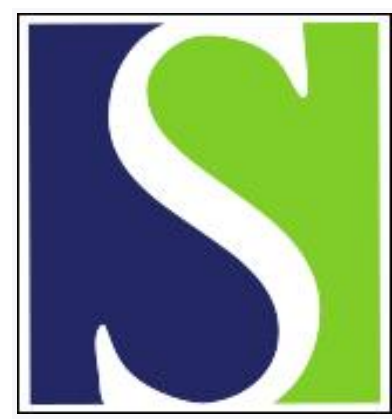

Scand J Work Environ Health 2007;33(5):379-386

https://doi.org/10.5271/sjweh.1157

Issue date: 31 Oct 2007

Risk of lung cancer according to mild steel and stainless steel welding

by Sørensen AR, Thulstrup AM, Hansen J, Ramlau-Hansen $\mathrm{CH}$, Meersohn A, Skytthe A, Bonde JP

Affiliation: Aarhus University Hospital, Nørrebrogade 44, Build 2c, DK-8000 Aarhus C, Denmark.

Refers to the following texts of the Journal: 2002;28(3):163-167

2006;32(1):22-31 1997;23(2):104-113

The following articles refer to this text: 2008;34(6):444-450;

2016;42(5):447-453; 2022;48(1):21-30

Key terms: chromium; epidemiology; lung cancer; lung cancer risk; metal worker; mild steel welding; occupation; stainless steel welding

This article in PubMed: www.ncbi.nlm.nih.gov/pubmed/17973064 


\title{
Risk of lung cancer according to mild steel and stainless steel welding
}

\author{
by Anita Rath Sørensen, ${ }^{1}$ Ane Marie Thulstrup, PhD, ${ }^{1}$ Johnni Hansen, PhD, ${ }^{2}$ Cecilia Høst Ramlau- \\ Hansen, PhD, ${ }^{1}$ Andrea Meersohn, ${ }^{2}$ Axel Skytthe, PhD, ${ }^{3}$ Jens Peter Bonde, $P h D^{1}$
}

\begin{abstract}
Sørensen AR, Thulstrup AM, Hansen J, Ramlau-Hansen CH, Meersohn A, Skytthe A, Bonde JP. Risk of lung cancer according to mild steel and stainless steel welding. Scand J Work Environ Health 2007;33(5):379-386.

Objectives Whether the elevated risk of lung cancer observed among welders is caused by welding emissions or by confounding from smoking or asbestos exposure is still not resolved. This question was addressed in a cohort with a long follow-up and quantified estimates of individual exposure to welding fume particulates.

Methods Male metal workers employed at least 1 year at one or more Danish stainless or mild steel industrial companies from 1964 through 1984 were enrolled in a cohort. Data on occupational and smoking history were obtained by questionnaire in 1986 . Welders in the cohort who started welding in 1960 or later $(\mathrm{N}=4539)$ were followed from April 1968 until December 2003, when information on cancer diagnosis was obtained from the Danish Cancer Registry. During the follow-up, 75 cases of primary lung cancer were identified. Lifetime accumulated exposure to welding fume particulates was estimated by combining questionnaire information and more than 1000 welding-process-specific measurements of fume particulates in the Danish welding industry.

Results The standardized incidence ratio (SIR) for lung cancer was increased among the welders [SIR 1.35, 95\% confidence interval (95\% CI) 1.06-1.70)]. Among the stainless steel welders, the risk increased significantly with increasing accumulative welding particulate exposure, while no exposure-response relation was found for mild steel welders, even after adjustment for tobacco smoking and asbestos exposure.

Conclusions The study corroborates earlier findings that welders have an increased risk of lung cancer. While exposure-response relations indicate carcinogenic effects related to stainless steel welding, it is still unresolved whether the mild steel welding process carries a carcinogenic risk.
\end{abstract}

Key terms chromium; epidemiology; lung cancer; metal worker; occupation.

A large number of studies indicates that the more than 2 million welders worldwide have an increased risk of lung cancer (1-9), but it is still unresolved whether constituents of the welding emissions are the cause or confer a risk or the observed association is due to confounding by tobacco smoking, asbestos exposure, or other factors (10).

Welders are exposed to vaporized metals that react with air-producing metal oxides, which condense and form respirable particulates that are likely to be deposited in the alveolar regions of the lung (11). Some experimental studies indicate that exposure to stainless steel alloys are carcinogenic in rats and hamsters (12). Most commonly, rodents have been exposed through the injection of particulates $(8,13)$ and not through the inhalation of welding fume particulates, and therefore the interpretation of the results is limited.

In contrast to mild steel welders, stainless steel welders are exposed to water-soluble nickel and hexavalent chromium. The latter is a well-established lung carcinogen (3, 13-16). Manual metal arc (MMA) mild steel welders are, in general, more exposed to welding fumes than metal active gas (MAG), metal inert gas (MIG), and tungsten inert gas (TIG) welders, and most metal workers use more than one method during their worklife.

A multicenter European study carried out in 19871989 by the International Agency for Research on Cancer

1 Aarhus University Hospital, Department of Occupational Medicine, Aarhus, Denmark.

2 Institute of Cancer Epidemiology, Danish Cancer Society, Copenhagen, Denmark.

3 Epidemiology, Institute of Public Health, University of Southern Denmark, Odense, Denmark.

Correspondence to: Dr AM Thulstrup, Department of Occupational Medicine, Aarhus University Hospital, Nørrebrogade 44, Build 2c, DK-8000 Aarhus C, Denmark. [E-mail: anemt@as.aaa.dk] 
(IARC) tested the hypothesis of an increased lung cancer risk among stainless steel welders. This study revealed an increased risk of lung cancer related to welding in general, but-contrary to expectations-the risk was elevated for mild steel welders and not for stainless steel welders $(4,6)$.

In 1990, IARC reviewed the scientific literature addressing the risk of cancer in relation to welding and reported rather consistent findings pointing to an excess risk of lung cancer of 30-50\% for welders (13). Welding fume was classified as possibly carcinogenic to humans (group 2B) (13). Since then, about 20 epidemiologic studies have been published corroborating an association between welding fume exposure and lung cancer, as well as other respiratory cancers, such as nasal cancer and larynx cancer $(1,5,6,17-21)$.

However, it is still considered uncertain whether the increased risk of lung cancer in welders is explained by welding fumes in general, is caused by specific welding processes such as stainless steel welding, or is the result of confounding by tobacco smoking or asbestos exposure or other factors $(6,14,22)$. With this background, we conducted this study to investigate whether the risk of lung cancer is related to the accumulated exposure to welding fume particulates among stainless steel and mild steel welders and to investigate whether associations, if any, remain when the effects of tobacco smoking and asbestos exposure are taken into account.

\section{Study population and methods}

\section{Study population}

The participants were selected from a cohort of 10059 male production workers employed at Danish companies handling stainless steel or mild steel for a minimum of 1 year within the period April 1964 through December 1984. The cohort members were enrolled from 74 companies, excluding shipyards due to possible asbestos exposure, employing about $60 \%$ of all Danish stainless steel welders from five large companies handling mild steel. The cohort members were male metal workers, alive as of April 1968 and born before 1 January 1965.

To minimize the incompleteness of the registration of the cohort members, the cohort was created in two phases with the use of two independent data sources (1, 23). In phase one, the companies included in the study were asked to establish a roster of men who had ever been employed as production workers. In phase two, additional company workers were identified from records of the Danish Pension Fund and the Danish Central Population Registry. All wage earners in Denmark have been compulsory members of this pension scheme since 1964, and records have been kept even when a person has retired, emigrated, or deceased. Data on job titles and departments of potential cohort members were obtained at each of the companies by means of standard interviews with managers, foremen, and long-term workers. Only the participants employed as mild steel welders, stainless steel welders, stainless steel grinders, or nonwelding or grinding production workers (eg, turners, fitters, warehousemen, but not apprentices or craftsmen) were admitted into the cohort.

During the autumn of 1986, the cohort members were sent a questionnaire on lifetime occupational exposures, tobacco smoking, and alcohol drinking habits and other exposures. Nonrespondents were contacted up to three times. Information on the subgroup of deceased ( $\mathrm{N}=675$ ), who had died in the period 1 April 1968 to 31 December 1985, was obtained in an interview with the spouse, next of kin, or colleagues. Responses were received for 8376 cohort members (83\%). Four questionnaires lacked information on basic characteristics, leading to 8372 answers suitable for analysis $(1,23)$. Of these, 6224 were from ever welders and 2148 (26\%) were from never-welding metalworkers.

For purposes of our analyses, we only included the 4539 ever welders that started welding work in 1960 or later because available data did not allow identification of incident cancer cases before 1 April 1968, when the registration of all Danish citizens according to a unique 10-digit personal identification number was complete. Apart from the 1685 ever welders that started welding before 1960, who were considered a survivor population, we also excluded the group of 2148 never welders since the group was considered too small and heterogeneous to constitute an appropriate internal reference group. Stainless steel welders were defined, regardless of mild steel welding, as ever stainless steel welders and the group of mild steel welders was defined as ever mild steel and never stainless steel welders on the basis of the information from the 1986 questionnaire study.

\section{Methods}

The observation period for the calculation of the risk of developing cancer began 1 April 1968 or on the date of being included in the cohort. The end of the follow-up was the date of death, date of emigration, date of first cancer diagnosis or 31 December 2003, whichever came first. Vital status, including date of death or emigration, was obtained by linkage to the national Civil Registration System. The welders with cancer diagnosed during the follow-up were ascertained by linkage to the Danish Cancer Registry. Both linkages were done with the use of the unique personal identification number as the key identifier.

Since 1943, the Danish Cancer Registry has received notifications from clinicians whenever a malignant 
neoplasm is diagnosed or when changes in the initial diagnosis occur. Tumors are coded in the Cancer Registry according to a Danish version of the 7th revision of the International Classification of Diseases (ICD) and, in addition, since 1978, according to the first version of the International Classification of Diseases for Oncology (ICD-O-1), which includes a 4-digit code for tumor morphology. To ensure comparability over decades, the Danish Cancer Registry has coded all entries according to the modified 7th ICD revision. If a person develops more than one primary cancer, each tumor is counted as an individual record; however, only the first primary lung cancer diagnosis was counted in this study.

By searching all primary lung cancer diagnoses in the Danish Cancer Registry for the period 1968-2003 (ICD-7=162), we identified 75 lung cancers among the 4539 welders. We also retrieved data on other respiratory cancers (ICD-7=140-148, 160-161, 163-64) and on all cancers with and without skin cancer.

The national rates specific for gender, age (5-year groups), and calendar time (5-year groups) were applied to the appropriate person-years under observation in each exposure group to obtain the number of cancers expected. Standardized incidence ratios (SIR) were calculated as the ratio of observed-to-expected cancers using a modified version of the Person-Years Software Program (MP Coleman, C Herman, A Douglas; United Kingdom). Significance and $95 \%$ confidence intervals ( $95 \% \mathrm{CI}$ ) were determined on the basis of the assumption that the observed number of cancer cases in any specific category follows a Poisson distribution.

\section{Assessment of asbestos exposure and tobacco smoking}

The questionnaire provided information on whether or not the worker had been directly exposed to asbestos. Comprehensive data on duration, timing, type, and amount of daily tobacco smoking was obtained by the use of a questionnaire.

\section{Assessment of exposure to welding fume particulates}

For each completed questionnaire, we extracted information on the first and last calendar year of welding and data on characteristics of welding activities throughout the worklife divided into decades (1960-1969, 19701979, 1980-1986). The characteristics included data on the welding method (MMA, MAG, and TIG), welding intermittence (average number of hours during a workshift), use of local exhaust ventilation (yes, sometimes, no), and welding in confined spaces (yes, sometimes, no) (table 1).

A welding exposure matrix with more than 1000 workplace measurements of particulates in ambient air was used to estimate accumulated exposure to welding fume particulates until 1985. The Danish Welding Institute and the National Institute of Occupational Health undertook the measurements in the Danish welding industry from 1971 to 1985 . Air samples were collected on filters placed in the breathing zone behind the welding helmet and are believed to provide representative welding-process-specific exposure data. The processspecific exposures in earlier decades were estimated by extrapolation based upon the declining trend of exposures that were observed from 1971 to 1985 for all types of welding processes. For mild steel MMA welding the average exposure levels for an 8-hour shift (no exhaust ventilation in semiclosed space) was $6.5 \mathrm{mg} / \mathrm{m}^{3}$ in 1971 and $5.2 \mathrm{mg} / \mathrm{m}^{3}$ in 1985 . The database provides geometric mean values for the welding processes specific for particulate exposure $\left(\mathrm{mg} / \mathrm{m}^{3}\right)(24)$.

Using the welding exposure matrix and the corresponding questionnaire data on decade, type of steel, welding method, intermittence, exhaust ventilation, and welding in confined spaces, we computed the product of the number of years and particulate concentration in each decade and summed over all decades to arrive at a summary measure of total lifelong exposure to welding fume particulates $\left(\mathrm{mg} / \mathrm{m}^{3} \times\right.$ years $)$

\section{Statistical analysis}

First, we performed external analyses comparing the incidence of lung cancer among the stainless steel welders and mild steel welders with the gender-, age-, and calendar-year-specific national rates. In addition, we analyzed the exposure-response relation between the estimates of accumulated exposure to welding fume particulates and the risk of lung cancer. These analyses were also performed according to the type of steel welded (stainless steel or mild steel).

In a second step, we performed internal analyses comparing the rate of respiratory cancer among stainless steel welders with the rate among mild steel welders in order to allow adjustment for tobacco smoking and asbestos exposure. Cox regression analysis was used to estimate hazard rate ratios (HRR), a measure of the relative risk of cancer incidence, with the Breslow method for ties and a time scale of years from the entry of the study (based on recorded calendar years). Two-sided 95\% confidence intervals (95\% CI) were calculated for the hazard rate ratios with the Wald's test of the Cox regression parameter. Observed time before the diagnosis probabilities were calculated by the Kaplan-Meier method. The results were adjusted for tobacco smoking exposure (current smoker in 1986 or ex-smoker in 1986 or never smoker), age (three age groups), and asbestos exposure (yes or no). A Cox regression analysis was performed with SAS 9.1 (SAS Institute, Raleigh, NC, USA). 


\section{Results}

The characteristics of the 4539 welders are given in table 1. The welders contributed 125762 person-years at risk. There were 75 primary lung cancers during the follow-up versus 55.4 expected (SIR 1.35, 95\% CI 1.06-1.70) (table 2). The number of all of the incident malignant neoplasms, including skin cancer, was 421, as compared with 410.8 expected (SIR 1.02, 95\% CI 0.93-1.13) (data not shown). The numbers of other respiratory cancers, including cancers of the nasal cavities and sinuses, the larynx, and the pleura, did not exceed the expected numbers (data not shown). The excess of lung cancer among the welders was approximately equally distributed for small-cell lung cancer and other types of pulmonary malignancies.

The relative risk tended to be nonsignificantly higher among the small group of never stainless steel welding mild steel welders than among the larger group of ever stainless steel welders. The exposure levels in the latter group were very heterogeneous, depending on the welding methods, and separating the high-level exposed MMA stainless steel welders from the low-level exposed TIG stainless steel welders showed an increased risk for MMA welders, although it was not significantly elevated (table 2). While the data did not indicate an increasing risk of lung cancer with increasing years of welding or accumulative welding fume exposure among the mild steel welders, we did observe a tendency for a positive exposure-response relation for the stainless steel welders. The risk increased with the numbers of years welding and with the accumulated exposure (table 2).

A significantly higher risk for lung cancer was found for the workers who started their career in the period 1960-1969 (table 2).

The internal analysis did not show an increased risk for the stainless steel welders compared with the mild steel welders (HRR 0.86, 95\% CI 0.52-1.42) after adjust-

Table 1. Characteristics of the 4539 welders at baseline (August 1986). (MMA = metal arc welding, $\mathrm{TIG}=$ tungsten inert gas)

\begin{tabular}{|c|c|c|c|c|c|c|c|c|}
\hline \multirow[t]{2}{*}{ Characteristic } & \multicolumn{4}{|c|}{ Stainless steel welders ${ }^{\mathrm{a}}(\mathrm{N}=3085)$} & \multicolumn{4}{|c|}{ Mild steel welders ${ }^{\mathrm{b}}(\mathrm{N}=1454)$} \\
\hline & N & $\%$ & Mean & SD & N & $\%$ & Mean & SD \\
\hline Age (years) & - & . & 37.3 & 9.8 & - & & 43.1 & 12.4 \\
\hline Ever smokers & 2419 & 78 & $\cdot$ & . & 1186 & 82 & $\cdot$ & $\cdot$ \\
\hline Current smokers & 1759 & 57 & $\cdot$ & . & 862 & 59 & $\cdot$ & $\cdot$ \\
\hline Ex-smokers & 650 & 21 & $\cdot$ & . & 324 & 22 & $\cdot$ & $\cdot$ \\
\hline \multicolumn{9}{|l|}{ Total number of years performing welding } \\
\hline Stainless steel welding & - & . & 8.3 & 6.3 & - & . & $\cdot$ & · \\
\hline Mild steel welding & - & $\cdot$ & 12.7 & 7.3 & - & $\cdot$ & 10.2 & 7.3 \\
\hline \multicolumn{9}{|l|}{ Estimated particulate exposure levels } \\
\hline \multicolumn{9}{|l|}{ Stainless steel welding } \\
\hline $\begin{array}{l}\text { Cumulative exposure across all years }\left(\mathrm{mg} / \mathrm{m}^{3} \times \text { years }\right) \\
\text { Eight-hour average exposure level }\left(\mathrm{mg} / \mathrm{m}^{3}\right)\end{array}$ & - & . & 10.6 & 11.9 & - & . & 34.4 & 28.8 \\
\hline $\begin{array}{l}\text { MMA } \\
\text { TIG and other methods }\end{array}$ & - & $\dot{.}$ & $\begin{array}{l}1.6 \\
0.6\end{array}$ & $\dot{r}$ & - & $\dot{.}$ & $\begin{array}{l}2.7 \\
2.6\end{array}$ & $\dot{r}$ \\
\hline Mild steel welding & & & & & & & & · \\
\hline $\begin{array}{l}\text { Cumulative exposure across all years }\left(\mathrm{mg} / \mathrm{m}^{3} \times \text { years }\right) \\
\text { Eight-hour average exposure level }\left(\mathrm{mg} / \mathrm{m}^{3}\right)\end{array}$ & $\begin{array}{l}- \\
-\end{array}$ & $\dot{r}$ & $\dot{.}$ & . & $\overline{-}$ & $\dot{r}$ & $\begin{array}{r}30.9 \\
3.0\end{array}$ & 29.3 \\
\hline \multicolumn{9}{|l|}{ Welding method } \\
\hline Ever MMA & 1934 & 78 & $\cdot$ & . & 2491 & 81 & $\cdot$ & · \\
\hline Never MMA) & 1151 & 37 & $\cdot$ & . & 594 & 19 & $\cdot$ & $\cdot$ \\
\hline \multicolumn{9}{|l|}{ Welding start ${ }^{c}$} \\
\hline $1960-1969$ & 1458 & 47 & $\cdot$ & . & 653 & 45 & $\cdot$ & · \\
\hline $1970-1979$ & 1292 & 42 & $\cdot$ & . & 598 & 41 & $\cdot$ & · \\
\hline 1980-1985 & 312 & 10 & $\cdot$ & . & 116 & 8 & $\cdot$ & · \\
\hline Missing data & 23 & 1 & . & . & 87 & 6 & . & . \\
\hline Use of local exhaust & 2082 & 68 & $\cdot$ & . & 765 & 53 & $\cdot$ & · \\
\hline Welding in confined spaces & 1556 & 50 & $\cdot$ & . & 315 & 22 & $\cdot$ & . \\
\hline Work with asbestos & 400 & 13 & . & . & 181 & 13 & . & . \\
\hline
\end{tabular}

a Ever stainless steel welders.

b Ever mild steel welders and never stainless steel.

${ }^{\mathrm{c}}$ All the methods are represented in each period. 
Table 2. Standardized incidence ratio (SIR) for primary lung cancer according to type and duration of welding and an estimate of accumulated exposure to welding fume particulates among 4539 male Danish welders followed from 1968 to 2003 . ${ }^{a}(95 \% \mathrm{Cl}=$ $95 \%$ confidence interval, $0=0 b s e r v e d$ number, $E=$ expected number, $\mathrm{SS}=$ stainless steel, $\mathrm{MS}=$ mild steel, $\mathrm{MMA}=$ metal arc welding)

\begin{tabular}{|c|c|c|c|c|c|c|}
\hline $\begin{array}{l}\text { Exposure } \\
\text { category }\end{array}$ & N & $\begin{array}{l}\text { Person- } \\
\text { years }\end{array}$ & 0 & E & SIR & $95 \% \mathrm{Cl}$ \\
\hline Ever welding & 4539 & 125762 & 75 & 55.4 & 1.35 & $1.06-1.70$ \\
\hline Ever SS welding & 3085 & 85426 & 34 & 29.6 & 1.15 & $0.78-1.60$ \\
\hline $\begin{array}{l}\text { Ever MMA- } \\
\text { SS welding } \\
\text { Never MMA- }\end{array}$ & 1934 & 54495 & 25 & 17.1 & 1.46 & $0.95-2.16$ \\
\hline $\begin{array}{l}\text { Never MMA- } \\
\text { SS welding }\end{array}$ & 1151 & 30931 & 9 & 16.5 & 0.72 & $0.35-1.36$ \\
\hline $\begin{array}{l}\text { Ever MS and } \\
\text { never SS } \\
\text { welding }\end{array}$ & 1454 & 40336 & 41 & 25.8 & 1.59 & 1. \\
\hline \multicolumn{7}{|c|}{ Calendar year when starting welding } \\
\hline $1960-1969$ & 2111 & 63267 & 48 & 34.1 & 1.41 & $1.04-1.87$ \\
\hline 1970 & 1890 & 50219 & 17 & 15.9 & 1.07 & $0.82-1.72$ \\
\hline 1980 & 428 & 10203 & 1 & 1.8 & 0.56 & $0.01-4.13$ \\
\hline Missing data & 110 & 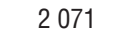 & 9 & $T$ & 42 & -4.60 \\
\hline \multicolumn{7}{|c|}{ Number of years welding } \\
\hline \multicolumn{7}{|c|}{ MS or SS welding } \\
\hline $1-10$ years & 2038 & 53283 & 25 & 20.8 & 1.20 & $0.78-1.77$ \\
\hline $11-20$ & 1618 & 4 & 25 & 7 & 1.27 & $0.82-1.87$ \\
\hline$\geq 21 \mathrm{~J}$ & 742 & $22 \varepsilon$ & 19 & 11.3 & 1.68 & $1.01-2.63$ \\
\hline Missing data & 141 & 3103 & 6 & 3.6 & 1.66 & $0.61-3.61$ \\
\hline \multicolumn{7}{|l|}{ SS welding } \\
\hline $1-10$ years & 2075 & 5 & 13 & 16.2 & 0.80 & -1.37 \\
\hline 11 & 806 & 2 & 9 & 9.6 & 0.94 & $0.43-1.78$ \\
\hline$\geq 21$ & 168 & 75 & 10 & 2.7 & 3.69 & $1.77-6.79$ \\
\hline Missing data & 36 & 72 & 2 & 1.1 & .06 & $0.21-6.70$ \\
\hline \multicolumn{7}{|l|}{ MS welding } \\
\hline $1-10$ years & $7 \varepsilon$ & & 18 & 11.6 & 55 & -2.45 \\
\hline $11-2$ & 431 & 12 & 11 & 8.1 & 1.36 & $0.68-2.43$ \\
\hline$\geq 21$ year & 171 & & 7 & 3.6 & 1.93 & $0.77-3.98$ \\
\hline Missing data & 67 & 1296 & 5 & 2.5 & 2.03 & $0.65-4.73$ \\
\hline \multicolumn{7}{|c|}{ Accumulated exposure to welding fume particulates $(\mathrm{mg} / \mathrm{m} 3 \times$ years $)$} \\
\hline \multicolumn{7}{|c|}{ MS or SS welding } \\
\hline $0-50$ years & 313 & 84381 & 44 & & 3 & 1.79 \\
\hline $51-10$ & 1073 & & 20 & 15 & & 2.05 \\
\hline $2 \pi 0$ & 262 & & 6 & 4.9 & 1.22 & $0.44-2.65$ \\
\hline Missing da & 67 & & 5 & 2.5 & 2.03 & $0.65-4.73$ \\
\hline \multicolumn{7}{|l|}{ SS welding } \\
\hline $0-10$ years & 1968 & 2685 & 17 & 18.2 & .93 & 1.49 \\
\hline & 643 & & 7 & 5.7 & 1.23 & $0.49-2.53$ \\
\hline$<20$ years & 474 & 14302 & 10 & 5.7 & 1.75 & $0.84-3.23$ \\
\hline \multicolumn{7}{|l|}{ MS welding } \\
\hline $0-30$ years & 846 & 23 & 13 & 11.5 & 1.13 & $0.60-2.93$ \\
\hline $31-60$ years & 328 & 9385 & 15 & 6.4 & 2.33 & $1.30-3.85$ \\
\hline$>60 y$ & 213 & 6636 & 8 & 5.4 & 1.49 & $0.64-2.93$ \\
\hline Missing data & 67 & 1296 & 5 & 2.5 & 2.03 & $0.65-4.73$ \\
\hline
\end{tabular}

ment for age, smoking exposure, and asbestos exposure (table 3). However, within the group of ever stainless steel welders, we observed a nonsignificant increased risk for the ever MMA welders when they were compared with all the other stainless steel welders (SIR 1.94, 95\% CI 0.88-4.28). Moreover, while we did not find clear indications of exposure-response relationships according
Table 3. Adjusted hazard rate ratios (HRR) for primary lung cancer among 1454 ever mild steel (MS) welders and never stainless steel (SS) welders and 3085 ever stainless steel welders among the 4539 welders. $^{\text {a }}$

\begin{tabular}{|c|c|c|c|c|}
\hline & $N^{b}$ & Cases & Adjusted HRR ${ }^{c}$ & $95 \% \mathrm{Cl}$ \\
\hline \multicolumn{5}{|l|}{ Type of welding } \\
\hline MS never SS ${ }^{d}$ & 1454 & 43 & 1 & .. \\
\hline SS & 3085 & 32 & 0.86 & $0.52-1.42$ \\
\hline \multicolumn{5}{|c|}{ Duration of welding } \\
\hline \multicolumn{5}{|l|}{ All welders } \\
\hline $0-5$ years $^{d}$ & 1065 & 20 & 1 & .. \\
\hline $6-15$ years & 1969 & 27 & 1.47 & $0.73-2.92$ \\
\hline$\geq 16$ years & 1505 & 28 & 1.29 & $0.65-2.57$ \\
\hline \multicolumn{5}{|c|}{ MS never SS welders } \\
\hline $0-5$ years $^{d}$ & 530 & 16 & 1 & .. \\
\hline $6-15$ years & 582 & 19 & 1.19 & $0.75-3.80$ \\
\hline$\geq 16$ years & 342 & 8 & 0.83 & $0.30-2.26$ \\
\hline \multicolumn{5}{|l|}{ SS welders } \\
\hline $0-5$ years $^{d}$ & 1278 & 13 & 1 & .. \\
\hline $6-10$ years & 833 & 1 & 0.17 & $0.02-1.28$ \\
\hline$\geq 11$ years & 974 & 18 & 1.07 & $0.50-2.28$ \\
\hline \multicolumn{5}{|c|}{ Cumulative exposure estimate $\left(\mathrm{mg} / \mathrm{m}^{3} \times\right.$ years $)$} \\
\hline \multicolumn{5}{|l|}{ All welders } \\
\hline $0-15$ years $^{d}$ & 1280 & 13 & 1 & .. \\
\hline $16-60$ years & 2189 & 34 & 2.05 & $1.02-4.09$ \\
\hline$\geq 61$ years & 1003 & 23 & 1.78 & $0.84-3.66$ \\
\hline \multicolumn{5}{|c|}{ MS never SS welders } \\
\hline $0-10$ years $^{d}$ & 399 & 4 & 1 & .. \\
\hline $11-50$ years & 682 & 26 & 3.29 & $0.97-11.1$ \\
\hline$\geq 51$ years & 306 & 8 & 1.79 & $0.46-6.99$ \\
\hline \multicolumn{5}{|l|}{ SS welders } \\
\hline $0-5$ years $^{d}$ & 1290 & 11 & 1 & .. \\
\hline $6-10$ years & 1072 & 6 & 1.18 & $0.40-3.51$ \\
\hline$\geq 11$ years & 723 & 15 & 2.34 & $1.03-5.28$ \\
\hline
\end{tabular}

a Boldface font has been used to indicate $95 \%$ statistical significance.

${ }^{b}$ Numbers less than expected in the $\mathrm{N}$ column indicate missing values for one or more of the covariates in the survival analysis.

${ }^{c}$ HRR adjusted for age, tobacco smoking, and asbestos exposure.

${ }^{\mathrm{d}}$ Reference.

to the duration or accumulated level of exposure in mild steel welding, the risk increased with increasing accumulated exposure level among the stainless steel welders and reached statistical significance at the highest level (table 3). As expected, age, smoking exposure, and asbestos exposure were all associated with a statistically significant increased risk of lung cancer (data not shown). Those who smoked for more than 35 years had an almost eightfold increased risk for cancer when compared with the nonsmokers after adjustment for age, asbestos, and welding exposure.

\section{Discussion}

The risk of lung cancer was increased by $35 \%$ among the ever welders when they were compared with the general population, while the risk of all cancers, including skin 
cancer, was very close to the expected level. Ever mild steel welders but never stainless steel welders had the highest relative risk, but the risk was not clearly related to an estimate of life-long accumulated exposure to welding fume particulates or crude indicators of total exposure as the number of years welded. The risk of lung cancer was less elevated among the ever stainless steel welders but exposure to welding emissions among stainless steel welders is highly heterogeneous, depending on the applied welding methods. Particle emissions are much higher in MMA welding than in TIG welding, and exposure to hexavalent chromium is orders of magnitude higher in MMA welding. In the latter type of welding, most of the chromium emissions are in trivalent form (25). It is therefore of interest that, within the group of ever stainless steel welders, the risk was only elevated among the ever MMA welders, but not among the welders that predominantly used the TIG-welding method. Moreover, among the ever stainless steel welders, the risk was related to the numbers of years the welding of stainless steel was done, and the risk increased with the estimate of accumulated exposure to welding fume particulates. The latter accounts for variation in exposure levels across calendar time, use of exhaust ventilation, welding in confined spaces, and number of hours daily welding in addition to the number of years of welding and applied welding methods. Our internal analyses showed no increased risk of lung cancers among stainless steel welders when they were compared with mild steel welders, but, again, exposure-response relations were observed in relation to welding stainless steel but not to welding mild steel.

The complete cohort comprised 6224 welders with 175288 person-years in the follow-up period of 1968 2003, but we restricted our analyses to welders that started welding in 1960 or later. This approach reduced the number of welders available for study by $27 \%$, the person-years of follow-up by $28 \%$, and the number of lung cancer cases by 81 (from 156 to 75 incident cases), but it was necessary to minimize selection bias. We were unfortunately not able to identify cancer diagnoses before 1968. Assuming that welding would not increase the risk of lung cancer the first 8 years, we only included workers that started welding in 1960 or later.

The main strengths of our study are the long followup period, spanning about 35 years, individual data on smoking and asbestos exposure, and the comprehensive quantified exposure assessment. Nevertheless, the latter also has limitations.

Information on individual welding tasks during the entire worklife was obtained up to 20 years after the work was actually performed, and the accuracy of the recall of details with respect to welding processes and the time spent with welding and work conditions are questionable. For instance, the use of exhaust and working in confined spaces have major impacts on welding exposure levels, but reliable data may be difficult to retrieve retrospectively. Moreover, the use of different welding techniques and materials across short time periods can only partly be accounted for in data collection and computations. Although our exposure estimation took several welding characteristics with high impact on exposure levels (as calendar time, welding technology, and work conditions) into account, there was a large residual variation in the exposure levels that the geometric mean values did not account for. This situation may, however, be less of a problem since this large variation was observed for welders across the workshift and across different workshifts so that group averages may provide a more reliable estimate of exposure than, for instance, point measurements.

Moreover, background exposure, dust exposures from grinding and other work processes, and less frequent welding techniques were not accounted for. It must be acknowledged that the evaluation of the validity of the exposure assessment only applied to the period 1950-1985. In addition, we do not know whether the workers continued welding or working as described in the questionnaire in August 1986.

The level of exposure to fume particulate from stainless steel welding in this cohort averaged $1.6 \mathrm{mg} / \mathrm{m}^{3}$ for an 8-hour workshift among the MMA welders, and the occupational threshold limits in Denmark today are 0.5 $\mathrm{mg} / \mathrm{m}^{3}$ for MMA stainless steel welding and $1.1 \mathrm{mg} / \mathrm{m}^{3}$ for TIG stainless steel welding, the proportion of soluble hexavalent chromium in the emission of particulates being considerably lower in the latter process. The average exposure for mild steel particulates in our cohort is also above the present threshold limit. The average exposure to mild steel particulate emissions among all of the welders through all of the years was estimated to be $3.0 \mathrm{mg} / \mathrm{m}^{3}$ per day, and the threshold limits are between $1.6 \mathrm{mg} / \mathrm{m}^{3}$ and $1.7 \mathrm{mg} / \mathrm{m}^{3}$ per day, depending on the welding process.

However, the average exposure level may have been low when compared with the level for welding, for instance, in shipyards. In Denmark, many precautions against welding fume exposure and asbestos exposure have been taken since 1980. In general, stainless steel welders are not as exposed to particulates as mild steel welders, and the most prevalent technique used for stainless steel welding, the TIG welding process, emits fewer fumes than the most prevalent mild steel welding technique.

The increased risk of lung cancer among mild steel welders is consistent with those found in a large number of earlier studies summarized in meta-analyses with updates $(4,18,22)$. Earlier studies have found no clear indications that the risk is related to various measures of welding exposure (18). In addition, this study did not 
reveal any clear relation between lung cancer risk and the estimate of exposure to fume particulates. However, the lack of a exposure-response relation cannot be taken as strong evidence that mild steel welding does not confer a risk because of the limitations of the exposure estimation already discussed. Thus the question about the carcinogenic properties of mild steel welding is still unresolved. On the other hand, the findings of this study provide support for the hypothesis that stainless steel welding increases the risk of lung cancer because the exposure estimation that accounts for the heterogeneous exposure conditions reveals a significant exposure-response relation. This finding is consistent with that of a Swedish study that indicated that welders exposed to high levels of chromium have a higher risk for cancer of the trachea, bronchus, and lung than welders exposed to low levels of chromium $(2,3)$ and those of several other studies (26). Furthermore, the finding is biologically highly plausible (25), and the association did not disappear when smoking and asbestos exposure was adjusted for in the survival analysis $(6,18,22)$. To test the hypothesis of higher risk for stainless steel welders, it seemed the most sensible to compare all welders that had been welding with stainless steel alloys, with only mild steel welders, even though many stainless steel welders were also mild steel welders. Pure and predominant stainless steel welding is rather uncommon.

We found an expected dose-response relation between the number of years smoking and the risk of lung cancer. We also found this dose-response relation between the actual number of cigarettes smoked and the risk of cancer. In addition, we found an excess risk of respiratory cancer for the participants who had worked with asbestos. These findings indicate reliable data from the questionnaires. However, the information obtained from the spouses and colleagues of the deceased is possibly vulnerable to recall bias (27).

In conclusion, the study corroborates numerous earlier studies that found both mild steel and stainless steel welders have a moderately increased risk of lung cancer. While exposure-response relations indicate carcinogenic effects related to the welding of stainless steel, it is still unresolved whether the mild steel welding process carries a risk per se or is related to other carcinogenic exposures.

\section{Acknowledgments}

This study was supported by grants from the Aarhus University Research Foundation (CVR-nr 104661 05).

Dr Klaus Stagis Hansen is thanked for providing access to the data of the welding cohort.

\section{References}

1. Hansen KS, Lauritsen JM, Skytthe A. Cancer incidence among mild steel and stainless steel welders and other metal workers. Am J Ind Med. 1996;30(4):373-82.

2. Milatou-Smith R, Gustavsson A, Sjögren B. Mortality among welders exposed to high and to low levels of hexavalent chromium and followed for more than 20 years. Int J Occup Environ Health. 1997;3(2):128-31.

3. Sjögren B, Gustavsson A, Hedström L. Mortality in two cohorts of welders exposed to high- and low-levels of hexavalent chromium. Scand J Work Environ Health. 1987;13(3):24751.

4. Steenland K. Ten-year update on mortality among mild-steel welders. Scand J Work Environ Health. 2002;28(3):163-7.

5. Lauritsen JM, Hansen KS. Lung cancer mortality in stainless steel and mild steel welders: a nested case-referent study. Am J Ind Med. 1996;30(4):383-91.

6. Simonato L, Fletcher AC, Andersen A, Anderson K, Becker $\mathrm{N}$, Chang-Claude $\mathrm{J}$ et al. A historical prospective study of European stainless steel, mild steel, and shipyard welders. $\mathrm{Br}$ J Ind Med. 1991;48(3):145-54.

7. Antonini JM. Health effects of welding. Crit Rev Toxicol. 2003;33(1):61-103.

8. Solano-Lopez C, Zeidler-Erdely PC, Hubbs AF, Reynolds SH, Roberts JR, Taylor MD et al. Welding fume exposure and associated inflammatory and hyperplastic changes in the lungs of tumor susceptible $\mathrm{a} / \mathrm{j}$ mice. Toxicol Pathol. 2006;34(4):36472.

9. Droste JH, Weyler JJ, Van Meerbeeck JP, Vermeire PA, van Sprundel MP. Occupational risk factors of lung cancer: a hospital based case-control study. Occup Environ Med. 1999;56(5):322-7.

10. Shields PG. Molecular epidemiology of smoking and lung cancer. Oncogene. 2002;21(45):6870-6.

11. Antonini JM, Lewis AB, Roberts JR, Whaley DA. Pulmonary effects of welding fumes: review of worker and experimental animal studies. Am J Ind Med. 2003;43(4):350-60.

12. Antonini JM, Leonard SS, Roberts JR, Solano-Lopez C, Young $\mathrm{SH}$, Shi $\mathrm{X}$ et al. Effect of stainless steel manual metal arc welding fume on free radical production, DNA damage, and apoptosis induction. Mol Cell Biochem. 2005;279(1-2):17-23.

13. Chromium, nickel and welding. Lyon: International Agency for Research on Cancer (IARC); 1990. IARC Monographs on the Evaluation of Carcinogenic Risks to Humans, volume 49, p 1-648. Erratum in: IARC Monogr Eval Carcinog Risks Hum 1991;51:483.

14. Langård S. Nickel-related cancer in welders. Sci Total Environ. 1994;148(2-3):303-9.

15. Russo P, Catassi A, Cesario A, Imperatori A, Rotolo N, Fini M, et al. Molecular mechanisms of hexavalent chromium-induced apoptosis in human bronchoalveolar cells. Am J Respir Cell Mol Biol. 2005;33(6):589-600.

16. Kuo CY, Wong RH, Lin JY, Lai JC, Lee H. Accumulation of chromium and nickel metals in lung tumors from lung cancer patients in Taiwan. J Toxicol Environ Health A. 2006;69(14):1337-44.

17. Gustavsson P, Jakobsson R, Johansson H, Lewin F, Norell $\mathrm{S}$, Rutkvist LE. Occupational exposures and squamous cell carcinoma of the oral cavity, pharynx, larynx, and oesophagus: a case-control study in Sweden. Occup Environ Med. 1998;55(6):393-400.

18. Ambroise D, Wild P, Moulin JJ. Update of a meta-analysis 
on lung cancer and welding. Scand J Work Environ Health. 2006;32(1):22-31.

19. Jockel KH, Ahrens W, Pohlabeln H, Bolm-Audorff U, Muller $\mathrm{KM}$. Lung cancer risk and welding: results from a case-control study in Germany. Am J Ind Med. 1998;33(4):313-20.

20. Dixon AJ, Dixon BF. Ultraviolet radiation from welding and possible risk of skin and ocular malignancy. Med J Aust. 2004;181(3):155-7.

21. Hernberg S, Westerholm P, Schultz-Larsen K, Degerth R, Kuosma E, Englund A, et al. Nasal and sinonasal cancer: connection with occupational exposures in Denmark, Finland and Sweden. Scand J Work Environ Health. 1983;9(4):315-26.

22. Moulin JJ. A meta-analysis of epidemiologic studies of lung cancer in welders. Scand J Work Environ Health. 1997;23(2):104-13.
23. Bonde JP, Hansen KS, Levine RJ. Fertility among Danish male welders. Scand J Work Environ Health. 1990;16(5):315-22.

24. Hansen, E. B. Eksponeringsdata for luftforurening ved svejsning [Exposure data on welding emissions]. Copenhagen: The Welding Institute; 1988. Report 89.59.

25. Langård S. Biological and environmental aspects of chromium. Amsterdam: Elsevier biomedical; 1982.

26. Sjögren B, Hansen KS, Kjuus H, Persson PG. Exposure to stainless steel welding fumes and lung cancer: a meta-analysis. Occup Environ Med. 1994;51(5):335-6.

27. Hansen KS. Validity of occupational exposure and smoking data obtained from surviving spouses and colleagues. Am J Ind Med. 1996;30(4):392-7.

Received for publication: 18 January 2007 